DOI: https://doi.org/10.24867/16BE03Pajevic

\title{
METODE NENADGLEDANE SEGMENTACIJE SLIKE ZA MAPIRANJE STRESOM POGOĐENIH REGIONA POLJOPRIVREDNOG ZEMLJIŠTA
}

\section{UNSUPERVISED IMAGE SEGMENTATION METHODS FOR MAPPING STRESS- AFFECTED REGIONS OF AGRICULTURAL LAND}

Nina Pajević, Fakultet tehničkih nauka, Novi Sad

\section{Oblast - ELEKTROTEHNIKA I RAČUNARSTVO}

Kratak sadržaj - U okviru rada opisana je segmentacija Sentinel-2 satelitskih snimaka na osnovu izvedenih vegetacionih indeksa u cilju mapiranja stresom pogođenih regiona poljoprivrednog zemljišta. Baza podataka sastoji se od vremenske serije multispektralnih slika 48 poljoprivrednih parcela $u$ Vojvodini. Vremenska serija obuhvata slike za 13 datuma u periodu od marta do septembra 2020. godine. Primenjene su tri metode segmentacije: segmentacija postavljanjem praga, segmentacija upotrebom $k$ means algoritma, $i$ segmentacija upotrebom pyImSegm biblioteke. Segmentacijom prvom metodom nije uspešno detektovana cela oštećena površina, dok su druge dve metode pokazale dobru sposobnost mapiranja slabije razvijenih regiona.
\end{abstract}

Ključne reči: Segmentacija, Mašinsko učenje, Kompjuterska vizija, Sentinel-2

Abstract - The paper describes the segmentation of Sentinel-2 satellite images based on derived vegetation indices in order to map stress-affected regions of agricultural land. The database consists of a time series of multispectral images of 48 agricultural parcels in Vojvodina. The time series includes images for 13 dates in the period from March to September 2020. Three segmentation methods were applied: threshold segmentation, segmentation using the k-means algorithm, and segmentation using the pyImSegm library. The first damaged area was not successfully detected by segmentation with the first method, while the other two methods showed a good ability to map less developed regions.

Keywords: Segmentation, Machine learning, Computer vision, Sentinel-2

\section{UVOD}

Poljoprivredne parcele podložne su raznim negativnim uticajima koji mogu dovesti do smanjenja prinosa. Neki od faktora koji se odražavaju na razvoj kulture kao i vitalnost i potencijal klijavosti semena na parceli mogu biti suša, poplave i ostale vremenske nepogode koje zahvataju celu površinu parcele, ali i štetočine, bolesti, ili sastav zemljišta, koji mogu uticati samo na određene delove parcele.

\section{NAPOMENA:}

Ovaj rad proistekao je iz master rada čiji mentor je bio doc. dr Branko Brkljač.
Kako su poljoprivredne parcele uglavnom velikih površina i nepregledne sa Zemljine površine bez terenskog prolaska kroz celu parcelu, što je uglavnom nepraktično i vremenski vrlo zahtevno [1], detekcija problema ukoliko nije zahvaćena cela parcela (već postoje manje anomalije unutar parcele) predstavlja problem za poljoprivrednike.

Predmet rada jeste nenadgledana segmentacija multispektralnih slika poljoprivrednih parcela dobijenih pomoću satelita Sentinel-2 u svrhu detekcije (negativnih) anomalija unutar parcela koje bi mogle dovesti do smanjenja prinosa. Kombinovanjem različitih kanala multispektralne slike izvode se vegetacioni indeksi koji nose informacije o generalnom stanju useva, ali i o različitim fiziološkim parametrima biljke.

Razmotrena su tri pristupa rešavanju problema:

- segmentacija postavljanjem praga na osnovu raspodele vrednosti NDVI vegetacionog indeksa,

- segmentacija upotrebom k-means algoritma nad superpikselima multispektralne slike,

- segmentacija pomoću biblioteke pyImSegm.

\section{PODACI SA SENTINEL-2 SATELITA}

Sentinel-2 (S2) predstavlja satelit čiji cilj jeste fotografisanje Zemljine površine u srednje visokoj rezoluciji i u više spektralnih opsega [2]. Snimci dobijeni pomoću ovih satelita (pošto je u pitanju konstelacija od dva satelita, tzv. S2-A i S2-B) u prostornom domenu podeljeni su u granule (ploče) fiksne veličine kojima je predstavljena površina od $100 \mathrm{~km}^{2}$, pri čemu je vremenski razmak između dve slike iste površine 5 dana. Na svakom od dva satelita u konstelaciji nalazi se optički multispektralni instrument (MSI) koji meri Sunčevo zračenje reflektovano sa Zemlje u 13 spektralnih opsega (kanala), od kojih 4 opsega imaju prostornu rezoluciju od $10 \mathrm{~m}$ po pikselu, 6 opsega rezoluciju $20 \mathrm{~m}$ po pikselu, i 3 opsega rezoluciju $60 \mathrm{~m}$ po pikselu. Granula sadrži po jednu zasebnu sliku za svaki kanal. U ovom radu, pre upotrebe opisanih satelitskih slika bilo je potrebno interpolirati kanale sa manjom prostornom rezolucijom na rezoluciju od $10 \mathrm{~m}$.

\section{OPIS BAZE PODATAKA}

Satelitske slike korišćene u ovom radu preuzete su iz javno dostupne baze podataka Evropske svemirske agencije kroz program Copernicus za 13 datuma $\mathrm{u}$ periodu od marta do septembra 2020. godine. Parcele nad kojima je bilo potrebno izvršiti segmentaciju nalaze se u Vojvodini i zahvaćene su granulom sa oznakom 34TCR. 
Iz preuzetih satelitskih snimaka isečene su slike unapred određenih poljoprivrednih parcela iz digitalnog katastra. Parcela ukupno ima 48 i nepoznato je koje kulture su posađene na njima. Međutim, pošto je cilj detekcija anomalija unutar površine parcela bez obzira na njihov sadržaj, navedeno nije predstavljalo otežavajuću okolnost.

\subsection{Vegetacioni indeksi}

Kako je cilj rada bio izdvojiti delove parcele koji zaostaju u razvoju za ostatkom parcele, bila je potrebna informacija o stanju useva. Procena ove informacije može da se dobije na osnovu analize različitih kombinacija kanala multispektralne slike kako bi se izveli odgovarajući vegetacioni indeksi. Dati postupak izvlačenja informacije zasniva se na činjenici da način na koji biljke apsorbuju i reflektuju svetlost različitih frekvencija zavisi od fiziološkog stanja i faze razvoja u kojoj se nalaze.

Korišćeni vegetacioni i spektralni indeksi [3] ilustrovani su odgovarajućim indeksiranim slikama koršćenjm iste kolor mape na slici 1. i predstavljaju redom:

- NDVI (engl. Normalized Difference Vegetation Index)

- MSR (engl. Modified simple ratio)

- EVI (engl. Enhanced vegetation index)

- GARI (engl. Green Atmospherically Resistant Index)

- WDRVI (engl. Wide Dynamic Range Vegetation Index)

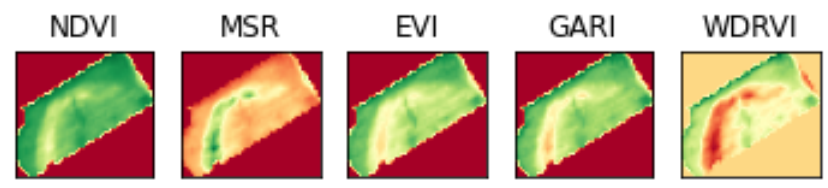

Slika 1. Korišćeni vegetacioni indeksi

\section{METODE SEGMENTACIJE}

S obzirom na to da su na parcelama posađene različite kulture i da se parcele prate i menjaju kroz vreme, odnosno usevi se razvijaju, vrednosti vegetacionih i spektralnih indeksa variraju od slike do slike. Iz tog razloga nije moguće postaviti jednu univerzalnu vrednost praga za segmentaciju ili napraviti metodu koja će raditi nad skupom slika, već je potrebno segmentaciji pristupiti na nivou jedne slike. Takođe, korisnicima ovakvog sistema za detekciju anomalija od koristi bi bilo da $\mathrm{u}$ svakom trenutku mogu da dobiju mapu segmenata na osnovu trenutnog stanja parcele. Sa druge strane, istorijski podaci mogu da posluže za detaljnije analize površina koje odgovaraju detektovanim segmentima (anomalijama) i predstavljaju potencijalan problem. Na taj način bilo bi moguće i prepoznavati vrste anomalija, od koje neke mogu biti prolaznog karaktera, a neke stalno prisutne kao posledica heterogenosti sastava zemljišta i njegove vlažnosti na nivou iste katastarske parcele. U ovom radu razmotrene su tri različite metode segmentacije za pojedinačne slike, bez istovremenog razmatranja čitave vremenske serije.

Vegetacioni indeks NDVI daje procenu opšteg stanja i zdravlja biljke i kao takav jedan je od najkorišćenijih izvedenih indeksa pri monitoringu vegetacije. Iz tog razloga rezultati metoda segmentacije evaluiraće se na osnovu NDVI slika parcela, npr. kao na slici 2.
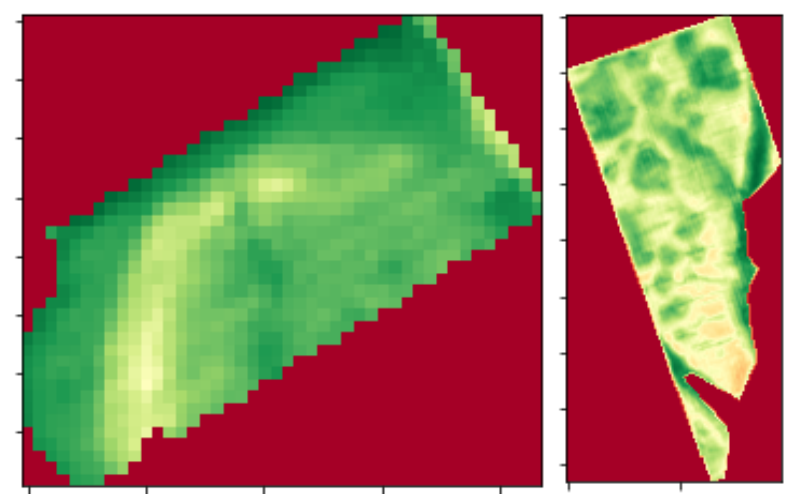

Slika 2. NDVI slike za dve različite parcele

\subsection{Segmentacija NDVI slike postavljanjem praga}

Data metoda zasniva se na činjenici da vegetacioni indeks NDVI u slučaju parcele gde nema anomalija ima približno normalnu raspodelu. Ukoliko na parceli postoje anomalije u vidu oštećenja dela parcele, data oštećenja se u raspodeli indeksa izražavaju kao jače izražen rep Gausove krive na mestima gde NDVI uzima niže vrednosti. U tom slučaju moguće je postaviti prag baziran na srednjoj vrednosti i standardnoj devijaciji raspodele.

Međutim, ako su oštećene površine suviše velike, to se ne manifestuje kao rep Gausove krive, nego se menja oblik cele krive i više nije moguće postaviti prag po tom principu. Zbog ovoga postaje teško detektovati celu oštećenu površinu, već se detektuju samo najoštećeniji delovi parcele.

\subsection{K-means algoritam}

Segmentacija u ovom slučaju realizovana je korišćenjem iterativnog $k$-means algoritma. K-means algoritam [4] bazira se na definisanju centroida ili težišta klastera odnosno grupa u prostoru obeležja (višedimenzionalnih merenja) i grupisanju uzoraka u klaster čiji centroid je najbliži.

Kako bi se redukovala računska složenost algoritma i postigla manja osetljivost na incijalizaciju početnog stanja, pre klasterizacije NDVI slika parcele je izdeljena na superpiksele [5] pomoću slic (engl. Simple Linear Iterative Clustering) algoritma. Superpikseli predstavljaju grupe, odnosno regione susednih piksela koji su slični po određenim karakteristikama (npr. intenzitet) i mogu se smatrati lokalnim homogenim zonama unutar satelitske slike. Formiranjem superpiksela doprinosi se smanjenju računske složenosti (jer su entiteti koji se grupišu superpikseli kojih ima značajno manj u odnosu na broj piksela), ali i tome da konačna klasterizacija bude robusnija i sa manje šuma (uzoraka pogrešno pridruženih definisanim centroidima).

Nakon rezultata klasterizacije NDVI slike odgovarajuće parcele formira se nova slika koja se sastoji od pet kanala, odnosno od pet vegetacionih i spektralnih indeksa: NDVI, WDRVI, MSR, GARI i EVI. Za datu višekanalnu sliku se na osnovu granica superpiksela dobijenih u prethodnom koraku (na osnovu NDVI) za svaki od pet kanala izračunaju prosečne vrednosti intenziteta originalnih piksela unutar svih definisanih superpiksela i generiše se konačna petokanalna slika u kojoj svi pikseli unutar pojedinačnih superpiksela jednog kanala imaju istu 
vrednost (izračunatu srednju vrednost). Motivacija za opisani postupak zasniva se na pretpostavci da će preterana segmentacija površine parcele kojoj odgovaraju granice superpiksela omogućiti lakše grupisanje sličnih zona unutar parcele. Pri tome su karakteristike zona opisane prosečnim vrednostima svakog od izračunatih indeksa na nivou odgovarajućeg superpiksela, tj. zone. Ovakav pristup često se označava i kao engl. "bottom-up approach“.

Nad tako dobijenom slikom u kojoj vrednosti piksela u svakom od kanala odgovaraju prosečnim intenzitetima na nivou superpiksela, vrednosti se dodatno normalizuju po kanalima kako bi mogla da se primeni PCA (engl. principal component analysis) metoda za redukciju dimenzionalnosti pomoću koje se broj kanala smanjuje sa pet na samo dva. Naredni korak je $k$-means klasterizacija u 3 očekivana klastera ili grupe (pozadina, bolji klaster i lošiji klaster).

Nakon klasterizacije superpiksela, na osnovu NDVI slike izračunava se srednja vrednost celokupnog boljeg klastera. Svi pikseli unutar boljeg klastera klasifikuju se kao delovi parcele na kojima nije prisutno oštećenje. Potom se prolazi kroz superpiksele lošijeg klastera i računa se odnos srednje vrednosti datog superpiksela i srednje vrednosti boljeg klastera. Ukoliko je izračunati odnos manji od $90 \%$ dati superpiksel se finalno klasifikuje kao oštećenje, dok vrednosti veće od $90 \%$ znače da se superpiksel klasifikuje kao neoštećen deo parcele.

\subsection{Biblioteka pyImSegm}

Dati pristup bazira se na upotrebi biblioteke pyImSegm u svrhu nenadgledane segmentacije, a koja je implementirana na osnovu algoritma opisanog u radu [6]. Algoritam za segmentaciju sastoji se od sledećih koraka:

1. Segmentacija slike na superpiksele

2. Kreiranje obeležja na osnovu superpiksela

3. Računanje verovatnoće pripadnosti klasi

4. Klasifikacija superpiksela korišćenjem metode sečenja grafa (engl. graph cut)

Segmentacija pomoću ove biblioteke izvršena je na slici sastavljenoj od tri vegetaciona i spektalna indeksa: WDRVI, MSR i GARI.

\section{REZULTATI}

Na slici 2 prikazane su NDVI slike za dve različite parcele.

\subsection{Rezultati metoda segmentacije}

Na slikama 3-7 prikazani su rezultati segmentacije za sve tri metode.

Belom bojom označeni su delovi parcele na kojima se nalaze anomalije, odnosno oštećenja. Crnom bojom označeni su delovi parcele koji nisu oštećeni, a sivom bojom označena je pozadina.

Vizuelnim upoređivanjem NDVI slika parcela i dobijenih rezultata dolazi se do zaključka da je prva metoda, odnosno metoda segmentacije pomoću praga nedovoljna da pravilno detektuje i obuhvati čitavu oštećenu površinu.

U slučaju druge i treće metode rezultati su dosta slični. Obe metode uhvatile su značajan deo površine parcele gde su vrednosti NDVI slabije, kao i zdrav deo parcele.
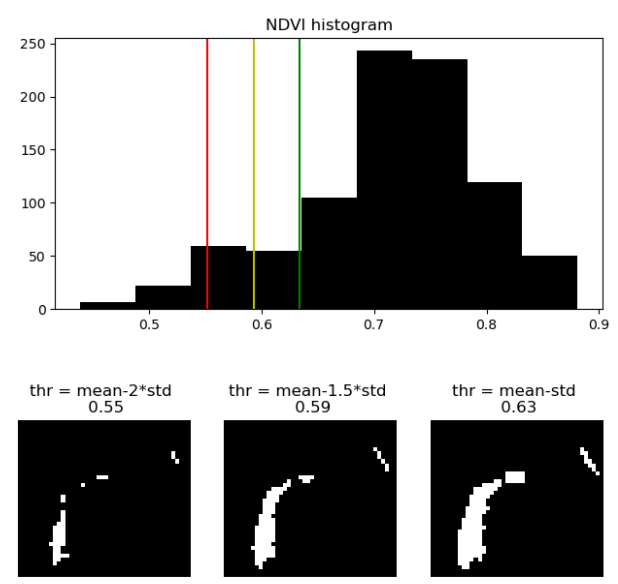

Slika 3. Rezultat segmentacije prvom metodom

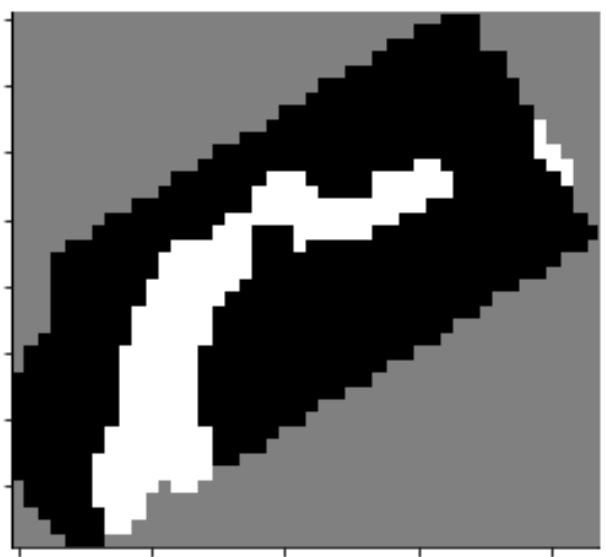

Slika 4. Rezultat segmentacije drugom metodom

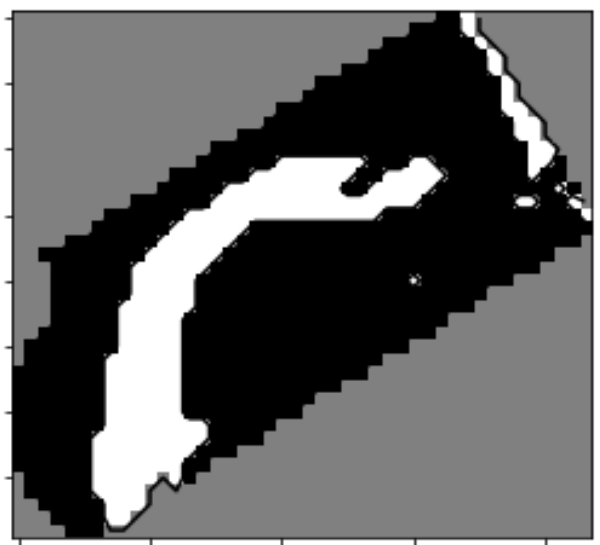

Slika 5. Rezultat segmentacije trećom metodom

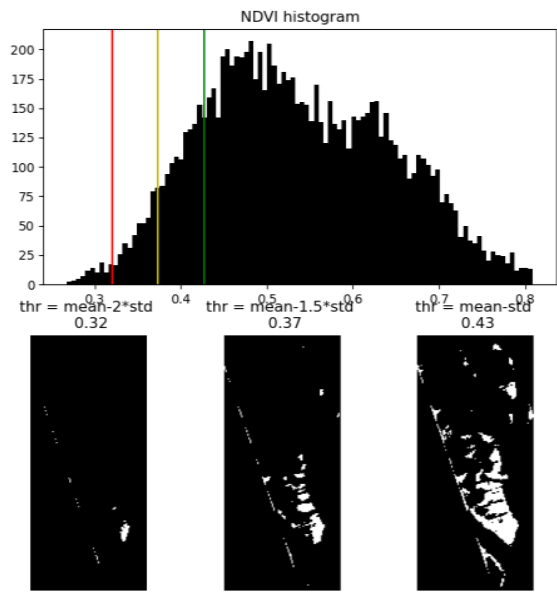

Slika 6. Rezultat segmentacije prvom metodom 


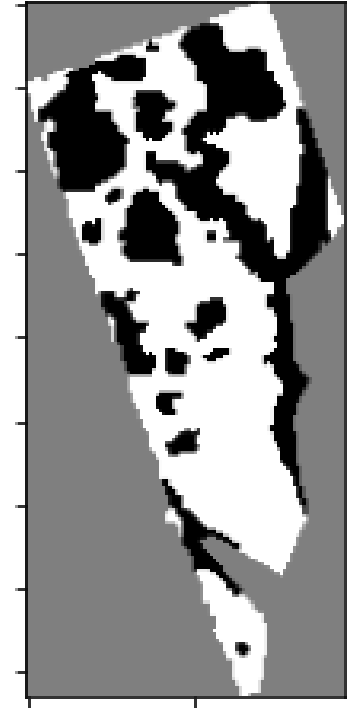

(a)

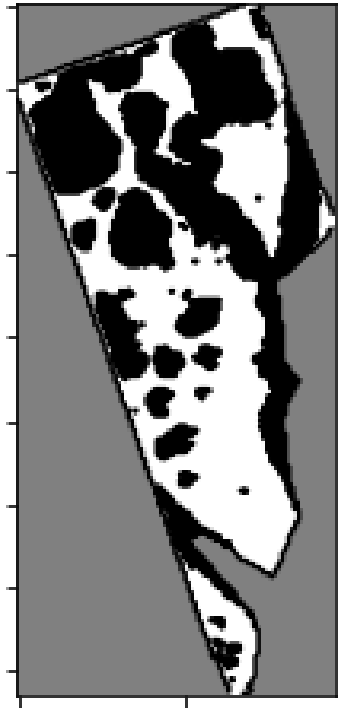

(b)
Slika 7. Rezultat segmentacije: drugom (a) i trećom metodom (b)

Rezultati treće metode pokazuju više uhvaćenih detalja prilikom segmentacije, međutim treba uzeti u obzir da je problem, odnosno zadatak ovog rada, bio da se segmentiraju delovi parcele koji zaostaju u razvoju za zdravim delom parcele. Samim tim, prednost druge metode jeste to što se može odrediti koliki stepen zaostatka u odnosu na celu parcelu je dopušten da bi se deo parcele smatrao zdravim. Ovo može predstavljati upravljački parametar za odgovarajući korisnički interfejs kojim bi se u zavisnosti od postavljenog praga generisale različite mape segmentacije.

$\mathrm{Na}$ taj način, ukoliko bi se dato rešenje upotrebljavalo u praksi, poljoprivrednici bi sami mogli da podešavaju segmentaciju u zavisnosti od potreba.

Segmentacijom parcela na opisani način moguće je pratiti razvoj useva kroz vreme. Na slici 8. prikazane su 3 slike iste katastarske parcele segmentirane drugom metodom za datume 02.08.2020, 17.08.2020. i 27.08.2020.
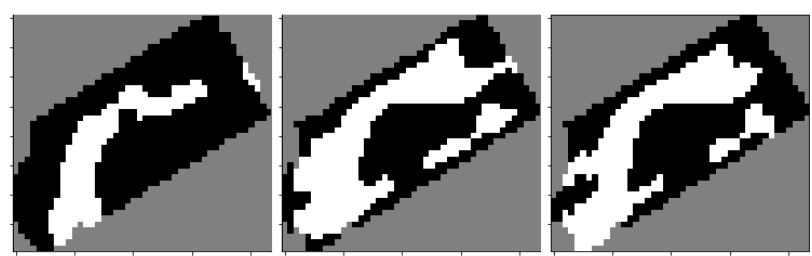

Slika 8. Rezultati segmentacije vremenske serije slika drugom metodom (datumi slika su 2.8.2020, 17.8.2020. i 27.8.2020, posmatrano sa leva na desno)

Praćenjem stanja parcele kroz vreme moguće je pravovremeno reagovati i sanirati štetu ukoliko dođe do pojave oštećenja. Segmentacijom ove vremenske serije slika utvrđeno je da je površina oštećenog dela parcele $22.72 \%$ cele površine parcele za prvi datum, $44.95 \%$ za drugi, i $40.5 \%$ za poslednji datum.

\section{ZAKLJUČAK}

U poljoprivredi se neretko dešava da manji delovi parcele zaostanu u razvoju zbog gubitaka vigora semena, pojave štetočina, bolesti. Upotrebom satelitskih slika u svrhu monitoringa parcela, praćenja razvoja i zdravlja useva, moguće je preduprediti i sanirati na vreme neke od negativnih pojava. Kreiranje rešenja za detekciju slabije razvijenih regiona poljoprivrednog zemljišta moglo bi biti od velike koristi poljoprivrednicima.

Predložene metode za segmentaciju mogle bi dodatno da se poboljšaju ukoliko bi se unapred identifikovali i definisali tipovi anomalija koje bi trebalo detektovati, i u skladu sa tim odredio minimalni skup merenja koja bi omogućila optimalno odlučivanje.

Takođe, predložena nenadgledana segmentacija može da predstavlja polaznu osnovu za identifikaciju tipova anomalija koje su od interesa za određenu vrstu useva, s obzirom da određene anomalije mogu predstavljati kombinaciju različitih uzroka. Tako identifikovani tipovi anomalija omogućili bi primenu metoda nadgledane segmentacije, bez obzira na raspoloživi skup merenja.

\section{LITERATURA}

[1] Zheng, Q., Huang, W., Cui, X., Shi, Y. and Liu, L., 2018. New Spectral Index for Detecting Wheat Yellow Rust Using Sentinel-2 Multispectral Imagery. Sensors, 18(3), p.868.

[2] Sentinel-2 User Handbook, https://sentinel.esa.int/d ocuments/247904/685211/Sentinel-2_User_Handbook (pristupljeno u septembru 2021.)

[3] Chemura, A., Mutanga, O. and Dube, T., 2016. Separability of coffee leaf rust infection levels with machine learning methods at Sentinel-2 MSI spectral resolutions. Precision Agriculture, 18(5), pp.859-881.

[4] https://stanford.edu/ cpiech/cs221/handouts/kmeans.htm 1 (pristupljeno u septembru 2021.)

[5] https://www.mathworks.com/help/images/ref/superpixels.html (pristupljeno u septembru 2021.)

[6] Borovec, J., Švihlík, J., Kybic, J. and Habart, D., 2017. Supervised and unsupervised segmentation using superpixels, model estimation, and graph cut. Journal of Electronic Imaging, 26(06), p.1.

\section{Kratka biografija:}

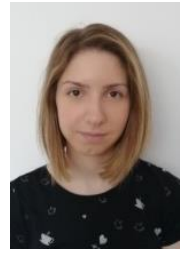

Nina Pajević rođena je u Novom Sadu 1997. god. Osnovne akademske studije na Departmanu za energetiku, elektroniku i telekomunikacije, Fakultet tehničkih nauka, Univerzitet u Novom Sadu, smer Obrada signala, uspešno je završila 2020. god. Na istom fakultetu i studijskom programu upisuje i master akademske studije i brani master rad 2021. godine. 